\title{
POSIBLES ECOS DE SAN JUAN DE LA CRUZ EN EL QUIJOTE DE $1605^{\circ}$
}

\section{Cervantes y la POESía Del Siglo XVI}

Como bien se sabe, la controvertida poesía de Cervantes y la lengua misma de nuestro primer escritor en el Quijote se corresponden más con la llaneza y naturalidad de los humanistas y poetas del siglo XVI (Juan de Valdés, Garcilaso de la Vega) que con el artificio barroco que se expande a comienzos del XVII (Góngora, Quevedo). Menéndez Pidal ha hecho observar que la fuerza expresiva de la lengua de Cervantes suele nutrirse de las más hondas raíces tradicionales, incluso en algunos giros humorísticos en que asoma kel artificioso ingenio del conceptismo incipientew'.

José Manuel Blecua, que figura entre los más diligentes investigadores de las fuentes poéticas de Cervantes, ha ilustrado suficientemente la marcada influencia de Garcilaso, Herrera y fray Luis de León en el autor del Quijote 2.

También Alberto Navarro estableció un adecuado paralelo, bajo el signo renacentista, entre Cervantes y fray Luis, destacando los

- El presente estudio contiene el texto de una ponencia, leída en sesión plenaria del Congreso Internacional sobre San Juan de la Cruz y San Ignacio de Loyola (dos polos hispánicos), en el Convento del Carmen de Pastrana, el día 3 de julio de 1990, bajo la dirección de Manuel Criado de Val.

Dado el tema de la ponencia, hemos creido de interés para los cervantistas reproducir su texto en las páginas de ANALES.

- Véase Ramón Menéndez Pidal, "La lengua castellana en el siglo XViI», Historia de España, t. XXVI: El siglo del Quijote (1580-1680), vol. II, Las Letras, las Artes. Madrid, Espasa-Calpe, 1986, p. 15.

2 Cfr. los dos artículos "Garcilaso y Cervantes" y «La poesía lírica de Cervantes", Cundernos de Insula, I, Homenaje a Cervantes en el IV Centenario de su Nacimiento, 1547-1947, pp. 141-187. 
entusiastas endecasílabos del primero, por boca de la ninfa y musa Caliope (Galatea, libro 6. ${ }^{\circ}$ ):

Fray Luis de León es el que digo,

a quien yo reverencio, adoro y sigo '.

En la temprana beatificación de Santa Teresa (1614), Cervantes compone una canción para celebrar los "éxtasis de la beata madre Teresa de Jesús». La mística de la escritora abulense enciende los versos del anciano escritor alcalaíno:

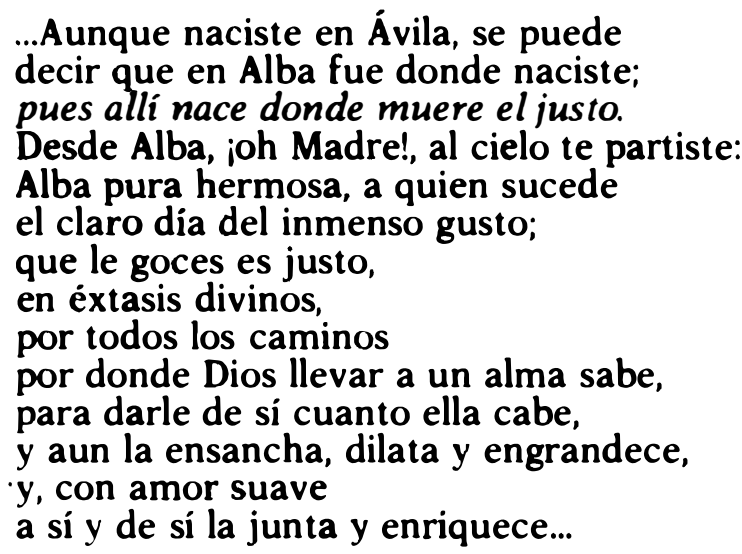

También puede ser de Cervantes el soneto con estrambote dedicado $A$ la beatificación de Teresa de Jesús, que comienza «Esa grandeza que mirando estaba / ino es maravilla octava en la grandezaw... Las festivas ponderaciones que contiene le aproximan -juramentos incluidos- al inspirado por el túmulo dedicado a las honras fúnebres de Felipe I en la catedral de Sevilla, el más famoso de Cervantes, que lo señaló "por honra principal de sus escritos", y es el que empieza "Voto a Dios, que me espanta esta grandeza.... 4 .

Queda, por tanto fuera de toda duda, que Cervantes había saboreado con deleite la mejor poesía española del siglo XVI, tanto la religiosa como la profana, así la impresa (Garcilaso, Herrera), como la difundida en copias manuscritas (Fray Luis de León). Sus composiciones teresianas indican una favorable disposición hacia la reforma de la orden carmelita, que llevaron a buen término con fervor y no pocos contratiempos Santa Teresa y San Juan de la Cruz.

Con todo, es difícil encontrar en las páginas del Quijote algún eco incuestionable de nuestro más elevado poeta místico del siglo XVI, San Juan de la Cruz, a quien se le deben acaso los

3 Vid. Alberto Navarro, "Cervantes y fray Luis de León», Anales Cervantinos, $\mathrm{X}, 1971$, pp. 3-14.

4 Vid. Cervantes, Poesías Completas, II, Edición de Vicente Gaos. Madrid, Clásicos Castalia, 1981, pp. 386-387, 412-413 y 376-377. 
mejores versos de la lengua española, en opinión de uno de los más eminentes poetas del siglo $\mathrm{XX}$, Jorge Guillén ${ }^{5}$. Ha sido otro excelente poeta y notable cervantista, Vicente Gaos (fallecido en 1980), quien apuntó esa posibilidad que ahora me propongo analizar.

\section{LA NOCHE OSCURA Y LA PRIMERA SALIDA DE DON QUIJOTE}

Con el epígrafe de tan peregrina relación, defendía Gaos la tesis de San Juan de la Cruz como una de las fuentes de Cervantes en breve ensayo de su jugoso libro Claves de Literatura Española (1971).

"Nadie ha observado, que yo sepa, - manifiesta Gaos- el paralelismo que ofrece la salida del místico hidalgo en busca de aventuras, narrada en el capítulo II de la primera parte, con la salida del alma a la busca de Dios en la Noche oscura, de San Juan*. Encuentra que el paralelismo entre los dos textos se extiende a un conjunto de palabras significativas y es demasiado estrecho para pensar en coincidencia puramente casual.

A todo lo cual añade otra frase del capítulo XVI (también de la primera parte del Quijote), donde cree hallar otra acomodación cervantina de la salida del alma en busca de Dios, en la noche oscura de la negación espiritual (o de la salida de la Esposa tras del místico Esposo) «con la salida de Maritornes a la busca del arriero en la noche oscura de la ventaw. Para Gaos, esta transformación de la mística en picaresca, es indudable aunque parezca irreverente y demuestra que el genio paródico de Cervantes no se limitó a los géneros caballeresco y pastoril.

Leemos en el Quijote: "Toda la venta estaba en silencio, y en toda ella no había otra luz que la que daba una lámpara, que colgada en medio del portal ardíaw. Y Gaos recuerda inmediatamente los versos de San Juan de la Cruz: sin otra luz y guia / sino la que en el corazón ardía.. La tensión cordial no cuenta tanto para el comentarista como el término lámpara, que también luce en el léxico de San Juan, o el ambiente creado por los «sosegados" huéspedes que duermen en la venta, la «maravillosa quietud», la "venturosa ocasión", "a escuras", etc. "

Algunos años más tarde, incorpora Vicente Gaos tales sugestiones a las notas y comentarios de su monumental edición crítica de Don Quijote, edición póstuma y a mi juicio la más valiosa de las que hoy podemos consultar del libro inmortal.

5 Vid. Jorge Gutllén, Lenguaje y poesía Algunos casos españoles. Madrid, Ed. Revista de Occidente, 1961. Apud kLenguaje insuficiente: San Juan de la Cruz o lo inefable misticon, pp. 95-142.

- Cfr. VICENTE GAOS, Claves de Literatura Española. I, Edad Media -siglo XXX. Madrid, Guadarrama, 1971, pp. 203-206. 
La nota 9 del capítulo II (Que trata de la primera salida que de su tierra hizo el ingenioso don Quijote) resume el paralelismo estilístico planteado en el ensayo anterior: «Esta salida recuerda, por los términos en que se describe, la salida del alma a la busca de Dios, en San Juan de la Cruz: "En una noche oscura" = una mañana, antes del dia "con ansias" = no quiso aguardar más tiempo, " oh dichosa ventura! = con grandisimo contento $y$ alborozo, "salí sin ser notada... en secreto" = sin dar parte a persona alguna; "que nadie me veía" = sin que nadie le viese, usegura" = con cuánta facilidac, "por la secreta escala, disfrazada" = por la puerta falsa; "parte donde nadie parecía" = al campo. Y concluye Gaos: «También la de Don Quijote es una salida espirituab.

Más adelante, entre las notas que ilustran el capítulo XVI, donde se nos cuenta el desdichado lance de don Quijote con Maritornes en el lóbrego camaranchón de la venta que él creía "famoso castillow, se reitera el juicio anterior. Y a los términos señalados ( klámpara», "quietud", "ocasión», "a escuras", etc.) se añade la concurrencia de heptasílabos y endecasílabos en la prosa cervantina del episodio (en un caso incluso con la rima en -ia empleada por el Santo): en toda ella no habia... colgada en medio del portal ardía..., sentándose en el lecho como pudo... tomando de la mano a la ventera.. eternamente escrito en mi memoria...?

La coincidencia de rima en -ia nos parece demasiado fácil por lo obligado de la desinencia verbal del pretérito imperfecto de indicativo en una narración. En cuanto a la abundancia de versos en la prosia cervantina - no solamente de heptasílabos y endecasílabos como correspondería en este caso a las liras de San Juan de la Cruz - ha sido advertida muchas veces en la prosa rítmica de Cervantes y en muy distintos capítulos. Juan Ramón Jiménez hizo notar la fluencia de octosílabos romanceriles en las páginas del Quijote. En sus palabras iniciales ya se señala un octosílabo, seguido de un endecasílabo: "En un lugar de la Mancha / de cuyo nombre no quiero acordarme..." En el capítulo que cuenta la aventura de los rebaños (I, 18), la parodia del tópico tradicional y caballeresco del catálogo de las huestes va ornamentado en una "prosa poética", que ya mereció los elogios de Capmany y Clemencín.

Por otra parte las equivalencias cotejadas por Gaos suelen abundar más en los términos de la interpretación del comentarista que en el mismo texto comentado. Nos parece observar esto en los siguientes ejemplos: "En una noche oscura" = una mañana, antes del día...; "segura" = con cuánta facilidack "por la secreta escala, disfrazada" = por la puerta falsa, wen parte donde nadie parecía» = al campo.

1 Consúltese Miguel de Cervantes Sanvedra, El ingenioso hidalgo don Quijote de la Mancha, I, Primera Parte. Edición crítica y comentario de Vicente Gaos. Madrid, Ed. Gredos, 1987, pp. 68-69 y 314. 
Admitimos, muy latu sensu, que la situación pueda ser comparable. Es decir, que "También la de don Quijote es una salida espirituab, en cuanto que la voluntad del Hidalgo ha resuelto cambiar el rumbo de su vida. En tal sentido, Arturo Marasso comparó hace bastantes años la primera salida de don Quijote con la Noche oscura de San Juan de la Cruz. El santo nos habla con el lenguaje de los símbolos, su lirismo ofrecerá siempre lejanías inalcanzables. "Cervantes conoce el anhelo de libertarse de la prisión y la noche oscura; va a descubrir y mostrar el camino de su héroe, a alcanzarse, a superarse, a trascender otra interior experiencia. ¡Oh dichosa ventura! Don Quijote salió «con grandísimo contentow. Don Quijote es todo alma. Es platónico. El alma es el hombre. También el alma es el hombre en los misticos. Se enciende la beata gloria de Dulcinea, entrevista en el cercano Toboso, como la princesa de un reino remoto, y en una visión sin par de idea platónica». La aventura caballeresca reviste trascendencia mística ${ }^{8}$. En otro. lugar, el mismo Marasso, en su estudio sobre kAlgunos aspectos del lirismo de San Juan de la Cruz" había señalado el origen místico de la escapada nocturna de la enamorada Tisbe en busca de Píramo; y Domingo Ynduráin admite el "recuerdo claro* de esta fábula en el inicio de la Noche oscura sanjuanista 9

El tratamiento profano de la noche en que los enamorados huyen de su confinamiento rutinario en busca de venturoso y claro día, no falta en los poetas del Renacimiento más celebrados por Cervantes: Garcilaso de la Vega, Gutierre de Cetina y Francisco de Figueroa. También es notorio el influjo de Garcilaso - y no sólo de su versión «a lo divino» por Sebastián de Córdoba- en la poesía de San Juan de la Cruz en su vena culta.

Dámaso Alonso ha evocado la figura de Juan de Yepes en Medina del Campo y en Salamanca. Allí, rel adolescente, indeciso aun en la vida, debió de beber la dulzura de Garcilaso, empaparse de la nueva música, hecha de ritmo y de amorosa nostalgia" ${ }^{10}$.

San Juan de la Cruz y Cervantes participan del vocabulario esencial garcilasiano, se embeben en su dulce melodía amorosa. Pero ies necesario que el autor alcalaino componga la fuga de su flamante caballero en busca del ideal soñado, mediante ecos - siquiera tenues y amortiguados- del alma encendida que escapa en pos del Amado En una noche oscura...?

Naturalmente que nos detenemos aquí en el mero examen estilístico y formal, sin atrevernos a entrar en la inefable doctrina

- Vid. Arturo Marasso, la invención del Quijote. Buenos Aires, Hachette, 1954, p. 47.

- Vid. San Juan de la Cruz, Poesía, en la excelente edición de Domingo Ynduráin, con documentadisima introducción. Madrid, Edics. Cátedra, 1983, pp. 207. 208.

10 Vid. Damaso Alonso, La poesia de San Juan de la Cruz (Desde esta ladera). Madrid, C.S.I.C., 1942, p. 97. 
mística de San Juan de la Cruz ni en sus elevados comentarios en prosa para explicar la "purgación" o Noche pasiva, frente a la Subida de! Monte Carmelo, que simbolizaría la Noche activa, en opinión de José Luis de Aranguren ".

Dentro de este limitado segmento literario, me parece el texto de Don Quijote bastante alejado del de la noche oscura de San Juan -aunque puedan acercarse en míticos y remotos orígenes-. Pero sí lo vemos en las cercanías de otra noche, la Noche serena de fray Luis de León, si recurrimos a otro pasaje. Leamos con atención el final elocuente del discurso de la pastora Marcela ante los que le inculpan por la muerte de Grisóstomo «Mis deseos... si de aquí salen, es a contemplar la hermosura del cielo, pasos con que camina el alma a su morada primera» $(I, 14)$.

Aquí creo ver un eco manifiesto del misticismo neoplatónico de fray Luis de León, tan admirado por Cervantes, como subrayábamos al comienzo de nuestra exposición ${ }^{12}$. Conceptos y expresiones verbales armonizan ajustadamente, en la frase resolutoria de Marcela, con las liras de la Noche serena del fraile agustino, dedicadas a Diego Olarte; se inflaman en un emocionante himno a la Naturaleza, como hechura de Dios:

\author{
Cuando contemplo el cielo \\ de innumerables luces adornado, \\ y miro hacia el suelo \\ de noche rodeado, \\ en sueño y en olvido sepultado... \\ la lengua dice al fin con voz doliente: \\ Morada de grandeza, \\ templo de caridad y hermosura, \\ el alma que a tu alteza \\ nació, ¿qué desventura \\ la tiene en esta cárcel baja, escura? ${ }^{13}$
}

No obstante, Vicente Gaos, fiel a su hallazgo, reitera en un apéndice final los argumentos expuestos en favor de la «vuelta a lo humanow de un texto religioso, tal como lo encuentra en el comienzo mismo de la obra: el paralelismo que ofrece la salida del mistico hidalgo en busca de aventuras con la salida del alma a la busca de Dios en la Noche oscura de San Juan de la Cruz. Sigue la reconsideración de Maritornes en busca de su arriero; pero como

"Cfr. J. L. Aranguren, San Juan de la Cruz Madrid, Edics. Júcar «Los Poetas", 1973, p. 91.

i2 Vid. Alberto Sánchez, "Tres comentarios al Quijotew, Cursos de Conferencias para Preuniversitarios. Madrid, Alejandro.Barbero Ed., 1960, p. 11.

13 Cito por Obras Completas castellanas de FraY LUIS DE LEÓN, con prólogo y notas del P. Félix García, O.S.A. Madrid, B.A.C., 1951, 2.: edición corregida y aumentada, p. 1451. 
no añade nuevas consideraciones para reforzar su tesis, no cabe insistir en este punto ${ }^{14}$.

Tampoco estimo concluyentes alguna que otra ligera alusión sanjuanista columbrada por Gaos en las páginas del primer Quijote, si bien no sostenidas con tanta convicción como las anteriores. Baste citar el caso de la fuga de Camila del domicilio conyugal, hacia el fin de la novela intercalada El curioso impertinente, donde leemos: "sin ser de nadie sentida, salió de casa" (DQ, I, 35). El comentarista se pregunta: «¿No habrá aquí otro eco de San Juan de la Cruz: «salí sin ser notada, / estando ya mi casa sosegada?" ${ }^{15}$.

Creo que el tema esencial de la fuga amorosa se expresará siempre en fórmulas verbales de alguna semejanza.

\section{AVENTURA NOCTURNA DEL CUERPO MUERTO (DQ, I, 19)}

Quizá en el episodio quijotesco del cuerpo muerto pisamos ya en terreno más firme, por lo que se refiere a la memoria de San Juan de la Cruz. No en la vertiente poética o estilística, sino en el recuerdo o alusión, largamente debatidos, de un suceso histórico post mortem del fraile carmelita.

Desde que Martín Fernández Navarrete en su biografía de Cervantes (Madrid, 1819) apuntó la posibilidad de que el sigiloso traslado nocturno de los restos mortales de San Juan de la Cruz, desde Úbeda a Segovia en 1593, había inspirado el capítulo de la aventura del cuerpo muerto en el Quijote, los cervantistas han aceptado, impugnado, o simplemente silenciado, tal posibilidad.

Diego Clemencín, el primer anotador importante de la obra, a comienzos del siglo XIX, recoge esta opinión bastante fundamentada. Cervantes andaba por Andalucía de comisiones oficiales cuando este suceso acaparaba la atención del público devoto y precisamente por los días en que nuestro autor andaba preocupado en la composición de su gran libro ${ }^{16}$. Claro está que también añade Clemencín situaciones caballerescas que pudieran dar pábulo a la aventura mencionada, como vemos en los capítulos LXXVI y LXXVII del Palmerin de Inglaterra, el CXXVII del Amadis de Gaula, o el XLIII, parte 3.a, de la Crónica de don Florisel de Niquea. Dos de estos libros de caballerías (el Amadís de Gaula y el Palmerín de Inglaterra) fueron salvados de morir en la hoguera, tras el donoso escrutinio que el cura y el barbero hicieron en la librería del ingenioso hidalgo $(\mathrm{I}, 6)$, gracias a los fervientes elogios que de ellos hicieron los censores. Prueba directa de las predilecciones

14 Véase el apéndice Cervantes y la Iglesia en el vol. III de su citada edición del Quijote, pp. 155-157.

is Vid. Don Quijote, edición cit. de V. Gaos, t. I, p. 715, nota 7.

16 Consúltese Cervantes, Don Quijote de La Mancha, Edición IV Centenario... enteramente comentada por Clemencín... Madrid, Ediciones Castilla, [1947], p. 1177. 
del autor del Quijote, que desmiente su declarada intención de terminar con la perniciosa lectura de los libros caballerescos.

El pasaje del Palmerín de Inglaterra es el que más se parece, en su arranque, al del Quijote. Incluso en las palabras, pues basta leer el epígrafe del citado capítulo LXXVII: «De lo que aconteció a Florián del Desierto en aquella aventura del cuerpo muerto de las andas" ${ }^{17}$.

Arturo Marasso, que admite la sugestión de Fernández de Navarrete y califica de "remota semejanza" el pasaje de Don Florisel traído por Clemencín (sin referirse para nada a la más firme cita del Palmerin de Inglaterra), añade por su cuenta una fuente literaria más: la traducción de la Eneida al castellano (y precisamente en la infortunada continuación de Mafeo Veggio) por Hernández de Velasco, tan leído por Cervantes. El piadoso Eneas hace llevar el cuerpo muerto de Turno ante su padre Dauno, en fúnebre comitiva nocturna, iluminada por el resplandor huidizo de las antorchas. «El cortejo, con majestad de apoteosis, va en la noche por el campo:

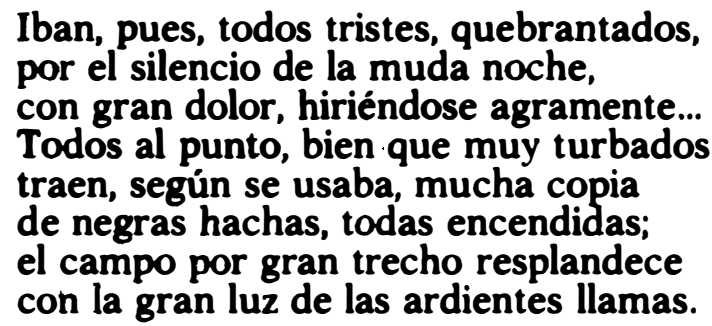

Don Quijote y Sancho ven en la noche oscura "que por el mismo camino que iban venian hacia ellos gran multitud de lumbres, que no parecían sino estrellas que se movian" (I, 19)m.

Para Marasso, la cuestión es clara, dentro del impulso de la creación poética: «Al poner la aventura del cuerpo muerto, desligándola de lo circunstancial, dentro de un plan épico, pisamos con don Quijote, la región sobrenatural de sus andanzas. Los hechos diarios que Cervantes pudo conocer o ignorar, se iluminan con la irradiación que les prestan el mito poético y la estricta tradición de la ley épica o de la ceremonian" 18.

Las mejores ediciones de Don Quijote en el siglo XX van registrando diversamente las aportaciones de la investigación y la crítica cervantina en este punto. Nos limitaremos a señalar algunas de las más consultadas.

"Estos dos libros de caballerias pueden hoy leerse en pulcras y recientes impresiones: el Palmerin de Inglaterra, presentado por Luis Alberto de Cuenca en Ediciones Miraguano, Madrid, Libro Primero, 1979; y el Amadís de Gaula de GARCI RODŔ́gUez DE MONTALvo, en edición de Juan Manuel Cacho Blecua. Madrid, Edics. Cátedra, 1987-1988, 2 vols.

1 Cfr. Arturo Marasso, obra citada en la nota 8, pp. 69-72. 
Martín de Riquer, en su muy difundida edición del Quijote resume el repetido capítulo del Palmerín de Inglaterra como fuente primordial de la aventura del cuerpo muerto; pero añade en una nota, mediado el capítulo, que kalgunos cervantistas suponen que aquí Cervantes tuvo presente la sigilosa traslación del cuerpo de San Juan de la Cruz" 19.

John Jay Allen, en su renovadora edición del primer Quijote, no incluye nota alguna en relación con las posibles fuentes del capítulo $19^{20}$.

En cuanto a la celebrada edición de Murillo, recoge la fuente caballeresca más próxima entre las reunidas por Clemencín (el Palmerín de Inglaterra) y se remite a la autoridad de Rodríguez Marín en cuanto al traslado de San Juan de la Cruz ${ }^{21}$.

Es muy curiosa la posición combativa del eminente cervantista Juan Bautista Avalle-Arce, que juzga desatinada la opinión de quienes mencionan el traslado de San Juan de la Cruz como posible fuente histórica y admite sin reservas solamente el influjo del Palmerín de Inglaterra. En efecto, la nota 11 de Avalle-Arce al capítulo 19 de su edición del Quijote (Primera Parte), dice así: "Varios comentaristas han buscado modelos históricos a esta aventura, y han desbarrado lamentablemente, como suponer que se trataba del traslado de los restos de San Juan de la Cruz o de don Juan de Austria, lo que no cuadra en absoluto con las circunstancias de esta aventura caballeresca. Lo que sí tiene fuerza actuante como testimonio literario (aquí parodiado) es el Libro del muy esforzado caballero Palmerin de Inglaterra..., I, LXXVII, "De lo que aconteció a Floriano del Desierto en aquella aventura del cuerpo muerto de las andas" ${ }^{22}$.

Que las circunstancias de esta aventura no cuadren en absoluto con las del traslado de los restos de San Juan de la Cruz parece una afirmación demasiado rotunda y apresurada, si leemos atentamente los datos geográficos y el motivo de la muerte, aducidos en el Quijote. Es completamente válida en lo que se refiere a don Juan de Austria, hipótesis bien rebatida muchos años antes. Volveremos sobre esto.

Resulta fácil comprobar que los editores y comentaristas del Quijote en el siglo XX suelen remitir en este particular a la autoridad de Francisco Rodríguez Marín, a veces sin mencionar siquiera a Fernández de Navarrete ni a Clemencín. Tal vez porque el

19 Vid. Cervantes, Don Quijote de La Mancha Edición, introducción y notas de Martín de Riquer. Barcelona, Planeta, 1962, pp. 184-185 y 189.

2o Vid. Cervantes, Don Quijote de La Mancha. Edición de John Jay Allen, ilustrada por Pilar Coomonte, Madrid, Edics. Cátedra, 1977, pp. 225-252.

21 Vid. Cerrvantes, Don Quijote de La Mancha, I. Edición, introducción y notas de Luis Andrés Murillo. Madrid, Clásicos Castalia, 1978, pp. 230-232.

22 Vid. Cervantes, Don Quijote de La Mancha, I. Edición, estudio y notas de Juan Bautista Avalle Arce. Madrid, Ed. Alhambra, 1979, p. 229. 
incansable erudito andaluz dio en su definitiva y póstuma edición de Don Quijote la explicación más completa del pasaje (Apéndice XV de la obra, bajo el epígrafe de «La aventura del cuerpo muerton).

Considera que es una de las más interesantes de la novela en su primera parte; y advierte en ella, al par que reminiscencias de los libros de caballerías, la de un whecho acaecido realmente". Rebate a Díez de Benjumea, quien dado al esoterismo en las interpretaciones del Quijote, había pensado en una alusión política a la muerte de don Juan de Austria, sin más punto de apoyo que las "calenturas pestilentes" de que se habla en el Quijote al explicar la causa de la muerte del caballero. Cortejón ya había razonado la imposibilidad de tal suposición porque el conjunto de las circunstancias referidas en la citada aventura son más bien aplicables «al austero y perseguido reformador carmelitaw.

Rodríguez Marín agrega, por su parte, un extracto del capítulo XVI de la Historia del Venerable Padre Fray Ivan de la Crvz. primer descalzo carmelita, compuesta por fray Jerónimo de San Joseph (Madrid, Diego Díaz de la Carrera, 1641). Se cuenta allí con pormenores inauditos el portentoso y secreto traslado, que en su momento fue muy lamentado y discutido en los pueblos de la alta Andalucía: «Sabida la muerte del siervo de Dios [1591] por D." Ana de Mercado y Peñalosa, su insigne devota, hizo apretadas diligencias, por medio de don Lucas Mercado su hermano, Oydor del Consejo Real de Castilla, con nuestro Padre fray Nicolás de Jesús María, Vicario General de la Reforma, para que mandase llevar el cuerpo del bendito Padre al Monasterio que él y ella habian fundado en Segoviaw.

El sigiloso traslado desde Úbeda (en el Quijote se habla de la vecina Baeza) hasta Segovia, se hizo en secreto, para no llamar la atención de los muchos oponentes, y dando rodeos en el camino, con detenciones en Jaén, Martos y Montilla. Se cuentan maravillosos incidentes que obstaculizaron la travesía, milagros y misteriosas apariciones ${ }^{23}$.

Incluso un hispanista británico de nuestros días, Gerald Brenan (fallecido en 1987), en su libro St. John of the Cross (Cambridge University Press, 1973), se refiere a estos sucesos en páginas apasionadas: "La muerte de San Juan de la Cruz fue seguida de unas extraordinarias escenas que sus bíógrafos recientes han preferido silenciar». La acalorada tensión entre Úbeda y Segovia para conservar el cuerpo del fraile carmelita (del que Ûbeda logró guardar, al fin, un brazo, un pie y algunos dedos) hace recordar a Brenan

23 Cfr. Cervantes, Don Quijote de La Mancha Nueva edición crítica con el comento refundido... dispuesta por Francisco Rodríguez Marín... Madrid, Ed. Atlas, 1949, t. IX, Apéndice XV: «La aventura del cuerpo muerton, pp. 226-230. 
«la disputa entre Sagunto y Zaragoza que aparece en el poema de Prudencio sobre el martirio de San Vicentew ${ }^{24}$.

Por último, si volvemos a la reciente edición del Quijote preparada por Vicente Gaos, tan atenta, como hemos visto, a las resonancias estilísticas de San Juan de la Cruz, advertiremos inmediatamente que el cervantista poeta recoge con todo cuidado lo que estima valioso de los comentaristas anteriores, al mismo tiempo que manifiesta de algún modo su personal criterio en cada caso.

En lo que se refiere a las fuentes de la aventura del cuerpo muerto, Gaos expone los criterios de Clemencín y Rodríguez Marín, sin excluir la mención de Navarrete. Admite la parodia de Palmerín y la reminiscencia más remota de Florisel añadiendo, como creencia admitida por varios cervantistas, la relación del episodio con el traslado de los restos de San Juan de la Cruz.

Por su cuenta, añade otra posible reminiscencia (ahora solamente verbal) de San Juan de la Cruz en este mismo capítulo. Se contiene en la declaración del héroe: «soy un caballero de la Mancha, llamado Don Quijote, y es mi oficio y ejercicio andar por el mundo enderezando entuertos y desfaciendo agraviosw. Afirmación que en este momento resulta irrisoria por las injustas lesiones de que ha sido víctima el bachiller Alonso López, natural de Alcobendas, atacado por el que desde ahora se llamará el Caballero de la Triste Figura, por iniciativa de Sancho.

Vicente Gaos anota puntualmente en este lugar: "Mi oficio $y$ ejercicio es uno de tantos binarios de Cervantes. Pero cabe pensar si no habrá aquí alusión a los versos de San Juan de la Cruz en el Cántico espiritual: ni ya tengo otro oficio / que ya sólo en amar es mi ejercicio ${ }^{25}$.

Cautelosamente, empieza por reconocer la predilección del estilo cervantino hacia las parejas de sinónimos, tanto de verbos (seguir y perseguir), como de adjetivos (atónito y suspenso), o de sustantivos como en el presente caso y muchos más, rasgo bien estudiado por los especialistas en la lengua de Don Quijote, desde Menéndez Pidal hasta Helmut Hatzfeld y Angel Rosenblat ${ }^{26}$.

24 Cito por la traducción castellana de Jaume Reig, del libro San Juan de la Cruz por GERALD BRENAN. Barcelona, Ed. Laia, 1974, pp. 101-102. - En la Bibliografía. selecta incluye, con breve comentario, las primeras biografías del Santo, publicadas entre 1616 y 1655 , reconociendo como la mejor, con mucha diferencia, la de Jerónimo de San José, O.C.D., consultada por Rodríguez Marín para ilustrar el repetido pasaje del Quijote.

25 Vid. Don Quijote, ed. cit. de Gaos, t. I, p. 373.

26 Cfr. el estudio de R. Menéndez Pidal, mencionado en la nota núm. 1, el libro de Helmut Hatzfeld, El "Quijote" como obra'de arte del lenguaje, Madrid, C.S.I.C., 1972, 2.: edición española, refundida y aumentada, reimpresión, y el de ANGel Rosenblat, La lengua del "Quijote". Madrid, Ed. Gredos, 1971.

Todavía puede consultarse con bastante utilidad la veterana investigación de JulJo CejADOR sobre La lengua de Cervantes. Gramática y diccionario de la lengua castellana en El ingenioso hidalgo Don Quijote de la Mancha. Prólogo de Rufino José Cuervo. Madrid, Tip. Jaime Ratés, 1905-1906, 2 vols. 
En el presente caso es muy notable la coincidencia, puesto que ejercicio no es frecuente sinónimo de oficio o profesión. Claro está que la clave simbólico-religiosa -según podemos leer en la declaración o explanación que de sus versos hace el poeta carmelitanos llevan muy lejos de la sencilla afirmación de Don Quijote:

Que ya sólo en amar es mi ejercicio.

"Como si dijera que ya todos estos oficios están puestos en ejercicio de amor de Dios, es a saber, que toda la habilidad de mi alma y cuerpo, memoria, entendimiento y voluntad, sentidos exteriores e interiores y apetitos de la parte sensitiva y espiritual, todo se mueve por amor y en amor, haciendo todo lo que hago con amor y padeciendo todo lo que padezco con sabor de amor; que es lo que quiso dar a entender David cuando dijo [Salmos, LVIII, 10]: Fortitudinem meam ad te custodiam Mi fortaleza guardaré para tíi” ${ }^{27}$.

No será ocioso recordar que en la lira 28 del Cántico espiritual, el vocablo que rima con el binomio oficio-ejercicio es precisamente servicio, henchido de claras resonancias caballerescas y amatorias en el léxico literario de los siglos XV y XVI. En vista de lo cual, el hontanar transparente del vocabulario se diluye en la neblina de un horizonte impreciso.

\section{CONCLUSIONES}

En atención a todo lo expuesto, creo que podemos establecer algunas conclusiones sin la ambiciosa pretensión de considerarlas como definitivas:

1.2 No parecen evidentes las resonancias poéticas de la Noche oscura, ni del Cántico espiritual de San Juan de la Cruz, en la prosa melódica de Don Quijote, dada la sencillez y amplitud del vocabulario que las aproxima y la lejanía del contexto que las separa.

2.: En la aventura del cuerpo muerto (DQ, I, 19), el planteamiento inicial, la comitiva enlutada de las antorchas y el reto del caballero son clara parodia del mundo caballeresco, con especial recuerdo del Palmerín de Inglaterra y de la continuación de la Eneida en la traducción castellana de Hernández de Velasco.

3." Todas las circunstancias que vienen a explicar el suceso, tan misterioso al principio, se corresponden exactamente con las que se dieron en el traslado de los restos de San Juan de la Cruz desde Ubeda a Segovia (con el simple cambio de Úbeda por la

27 Cito por la edición de SAN JUAN DE LA CRUz, El Cántico Espiritual, con prefacio de A. Alvarez de la Villa. Paris, Sociedad de Ediciones Louis-Michaud, s.f., p. 197. 
vecina población de Baeza). El caballero de las andas no había fallecido en lance de armas, como le sucedió a Fortibrán el Esforzado (en el Palmerín de Inglaterra) sino de unas calenturas como hubo de sufrir el carmelita descalzo. En fin, no acompañan al cuerpo muerto enanos deformes, doncellas gimientes o escuderos armados, sino eclesiásticos, vestidos de negras ropas talares.

4." Rodríguez Marín ha documentado la existencia real de un Alonso López, vecino de Úbeda, posiblemente inspirador del bachiller de Alcobendas, que acompañaba al cuerpo muerto y fue herido por Don Quijote. Alonso López fue uno de los compañeros de Cervantes en la cautividad de Argel. El propio Cervantes estuvo en Úbeda para sacar trigo en 1592, al año siguiente de la muerte del fraile carmelita, cuyos restos iban a ser trasladados a Segovia en 1593.

En el texto del Quijote se recogen inequívocamente rasgos que proceden del mito caballeresco y pormenores que concurren en un suceso histórico que encendió las piadosas discusiones de una población enfervorizada en el culto al fraile carmelita. De lo vago e impreciso en la muerte de Fortibrán el Esforzado - ¿cómo, cuándo y dónde?-, pasamos al muerto por unas fiebres y trasladado desde Baeza ( = Úbeda) a Segovia, frente a las innumerables rutas posibles. El novelista genial ha dado el paso de lo vago y genérico a lo concreto y real.

Todo lo cual viene a ilustrar, una vez más, la singular armonía establecida por Cervantes entre lo universal poético y lo particular histórico, en el rumbo de la tradicional doctrina aristotélica.

ALBERTO SÁNCHEZ 